\title{
INCENTIVE-ALIGNED CONJOINT ANALYSIS
}

\author{
Min Ding \\ Rajdeep Grewal \\ John Liechty
}

January 2004

$\underline{\text { Revised March } 2004}$

Revised May 2004

Min Ding is Assistant Professor of Marketing, Rajdeep Grewal is Assistant Professor of Marketing, and John Liechty is Assistant Professor of Marketing and Statistics, all are at the Smeal College of Business Administration, the Pennsylvania State University, University Park, PA, 16802-3007. The authors contributed equally to this manuscript. The authors acknowledge constructive comments from Gary Bolton, Eric Bradlow, Wayne DeSarbo, Jehoshua Eliashberg, Tony Kwasnica, Gary Lilien, and Arvind Ramgaswamy. The article benefited from the feedback of the Editor and two anonymous Journal of Marketing Research reviewers. This research was supported by the Marketing Department at Pennsylvania State University. The cooperation from New Chinatown restaurant at State College, PA, and the Laboratory for Economic Management and Auctions (LEMA) at PSU is greatly appreciated. 


\title{
INCENTIVE-ALIGNED CONJOINT ANALYSIS
}

\begin{abstract}
Because most conjoint studies are conducted in hypothetical situations with no consumption consequences for the participants, the extent to which the studies are able to uncover "true" consumer preference structures is questionable. Experimental economics literature, with its emphasis on incentive alignment and hypothetical bias, suggests that more realistic incentivealigned studies will result in stronger out-of-sample predictive performance of actual purchase behaviors and provide better estimates of consumer preference structures than hypothetical studies. To test this hypothesis, the authors design an experiment with conventional (hypothetical) conditions and their parallel incentive-aligned counterparts. Using Chinese dinner specials as the context, the authors conducted a field experiment in a Chinese restaurant during dinnertime. The results provide strong evidence in favor of incentive-aligned choice conjoint analysis, in that incentive-aligned choice conjoint outperforms hypothetical choice conjoint in out-of-sample predictions $(59 \%$ versus $26 \%$ for incentive-aligned choice conjoint and hypothetical choice conjoint, respectively for the top two choices). As expected, subjects in the incentive-aligned choice condition exhibit preference structures that are systematically different from the preference structures of subjects in the hypothetical condition. Most notably, the subjects in the incentive-aligned choice condition are more price sensitive and exhibit different heterogeneity patterns. To determine the robustness of these results, the authors conducted a second study that used snacks as the context and only considered the choice treatments. This study confirmed the results by again providing strong evidence in favor of incentive-aligned choice analysis in out-of-sample predictions (36\% versus $16 \%$ for incentive-aligned choice conjoint and hypothetical choice conjoint, respectively for the top two choices). The results provide a strong motivation for conjoint practitioners to consider conducting their studies in realistic settings using incentive structures that require participants to "live with" their decisions.
\end{abstract}


Conjoint analysis, which has developed into a widely applied methodology for making inferences about consumer preferences and uncovering empirical demand functions (Carrol and Green 1995), also has many substantive applications in marketing, such as those for new product development (e.g., Kohli and Majahan 1991), pricing (e.g., Mahajan, Green, and Goldberg 1982), segmentation (e.g., Green and Kreiger 1991), and positioning (e.g., Green and Kreiger 1992). Conjoint analysis also has been applied successfully in practice (Cattin and Wittink 1982; Wittink and Cattin 1989; Wittink, Vriens, and Burhenne 1994), and there is extensive literature on the subject (for reviews, see Green, Krieger, and Wind 2001; Green and Srinivasan 1978, 1990). As a result, there are many variants of conjoint analysis based on the way preference scores are elicited (e.g., ratings, rankings, self-explicated, constant sum, choice), the type of designs used (e.g., full factorial, fractional factorial, adaptive), the type of models estimated (e.g., regression, logit, probit, hierarchical Bayes), and the estimation procedures employed to make inferences (e.g., maximum likelihood, Markov Chain Monte Carlo). Despite these differences, most methods have certain common elements. Data collection requires consumers to rate, rank, or select alternative products, and the goal of the data analysis is to find the set of partworths that, given a compositional rule, is most consistent with the respondent's overall preferences (Green and Srinivasan 1978).

Although early research on conjoint analysis rarely used out-of-sample predictions to assess model validity, scholars have suggested that such predictions are the strongest means to assess the validity of conjoint studies (Green and Srinivasan 1990). As a result, three types of validation or prediction tasks_aggregate-level market share predictions (e.g., Srinivasan et al. 1981), individual-level predictions of purchase intentions (e.g., Leigh, MacKay, and Summers 1984), and individual-level predictions of actual behaviors (e.g., Srinivasan 1988; see also Green 
and Srinivasan 1990)—have dominated the conjoint landscape. However, there are limitations to each method.

First, scholars have attempted to predict real-world current (e.g., Davidson 1973; Page and Rosenbaum 1987) or future (e.g., Robinson 1980; Srinivasan et al. 1981) market share using conjoint tasks. Such aggregate-level predictions have confounding problems related to the effects of marketing mix variables other than product design. For example, in his conjoint study of North Atlantic Air, Robinson (1980) uses airfares, discounts, and travel restrictions, in addition to information obtained from the conjoint exercise, to predict future market shares. In such exercises, it becomes difficult to separate the marketing mix effects, such as advertising and promotions, from the conjoint task effects.

Second, predictions of purchase intentions are unreliable because stated preferences often differ from revealed preferences, which are derived from actual purchase behaviors (Green and Srinivasan 1990). Although attempts have been made to improve the reliability and validity of purchase intention predictions by using Pareto optimal choice sets in the prediction tasks (i.e., choice sets in which none of the alternatives is dominated by the remaining alternatives) (e.g., Elrod, Louviere, and Davey 1992; Johnson, Meyer, and Ghose 1989), they have not always been successful because non-Pareto, traditional holdout sets can sometimes be more difficult to predict than Pareto choice sets (Green, Helsen, and Shandler 1988). In addition, Pareto optimal choice sets offer no way to link purchase intention to actual purchase behavior.

Third, individual-level predictions of actual behavior usually are carried out through intervention studies, in which the researchers perform a conjoint exercise while consumers are involved in actual decision-making. For example, Srinivasan (1988), Srinivasan and Park (1997), and Wittink and Montgomery (1979) predict the jobs that MBA students will choose 
among multiple offers on the basis of self-explicated and rating scores. Wright and Kriewall (1980) predict whether high school seniors will apply to certain universities on the basis of student preferences revealed through a conjoint task. Because these intervention studies involve real decisions that are likely to impact the respondents in profound ways (e.g., the job preferences of MBA students; Wittink and Montgomery 1979), subjects are likely to be motivated to reveal their "true" preferences. Despite the merits of intervention studies, they often are not practical, because intervention tasks generally are not feasible.

In hypothetical data collection exercises, the subjects may not experience strong incentives to expend the cognitive efforts needed to provide researchers with an accurate answer. A rich literature in experimental economics argues that such data can be inconsistent, erratic, and, in many cases, untrustworthy (for example, see meta-studies on the role of incentives; Camerer and Hogarth 1999; Smith and Walker 1993). The theoretical underpinning of this argument is based on the induced value theory (Smith 1976), which states that three conditions must be satisfied to solicit incentive-compatible behavior: monotonicity, salience, and dominance. $^{\text {D }}$

The most relevant condition for conjoint analysis is salience, which requires that the reward be directly related to the decisions the subject makes during a study. Most practitioners of conjoint studies pay consumers some money for participation. However, paying a respondent a fixed amount is not salient, because there is no relationship between the respondent's performance/actions and the reward (money) he or she receives. As a result, there is no reason to

\footnotetext{
${ }^{1}$ Another setting in which consumers have an incentive to act in a manner that reveals their "true" preference is Internet-based, mass customization efforts that use consumers' preference ratings to personalize a decision support system. We thank an anonymous reviewer for highlighting this point.

${ }^{2}$ Monotonicity means respondents must prefer more reward to less and not become satiated as the reward increases. This requirement is easily satisfied if money is used as the reward. Dominance requires that the respondents' utilities from the experiment come predominantly from the reward medium and that other influences are negligible. A salient reward must be great enough to satisfy the dominance requirement.
} 
expect that the respondent's behavior during a study will be consistent with his or her behavior during a similar, real-world, economic activity. (In other words, there are neither rewards nor penalties for respondents to correctly or incorrectly state their preferences.) On the basis of a meta-study of 74 research papers, Camerer and Hogarth $(1999$, p. 8) find that salient incentives tend to "shift behavior away from an overly socially-desirable presentation of oneself to a more realistic one: when [salient] incentives are low subjects say they would be more risk-preferring and generous than they actually are when [salient] incentives are increased."

A related stream of literature explicitly studies hypothetical bias in the context of the contingent valuation method (for a review, see Diamond and Hausman, 1994). The contingent valuation method suggests that what subjects say they would do in hypothetical situations does not necessarily correspond to what they actually do; that is, stated preferences do not always match revealed preferences. For example, Bishop and Heberlein (1986) find in the context of deer hunting permits that willingness to pay values were significantly overstated in the hypothetical condition relative to the actual cash condition. List (2001) shows that sports card dealers significantly overstate their bids for a sports card in a hypothetical condition compared with the real action (\$107.89 versus \$59.56). Finally, List and Shogren (1998) find that the selling price for a gift is significantly higher in real situations than in hypothetical situations.

On the basis of the literature on incentive alignment and hypothetical bias, we hypothesize that state-of-art conjoint data collection techniques may fail to uncover preferences that align with actual purchase behavior due to the hypothetical settings in which the data are collected. In hypothetical research settings, respondents may discount their budget constraints or simply state preferences that are inconsistent with their actual behavior (e.g., because of a preference structure expected by peers). To induce realism in hypothetical tasks, we propose to 
use incentive structures that align with actual purchase behaviors. On the basis of the induced value theory (Smith 1976), we expect that an incentive-aligned conjoint analysis will outperform traditional hypothetical conjoint analysis in predicting actual behaviors. As a consequence, we also expect that the preference structure that incentive-aligned conjoint uncovers will be different from that of hypothetical conjoint analysis. Specifically, as suggested by the contingent valuation method (Diamond and Hausman 1994; List 2001), budget constraints tend to be discounted in hypothetical situations, so we expect that price will play a more prominent role in incentive-aligned conjoint. In addition, socially desirable answers, such as lower preference for red meats or higher willingness to donate money to social causes, are less likely in incentivealigned conditions (Camerer and Hogarth 1999), which may result in greater heterogeneity for socially desirables attributes. In other words, both subjects who want and those who do not want to choose a socially desirable alternative will tend to choose that alternative during a hypothetical setting, but in an incentive-aliened setting, those who do not want to choose the socially desirable alternative will tend to reject that alternative, and this will result in increased heterogeneity. In summary, we expect that incentive-aligned conjoint will (1) outperform traditional hypothetical conjoint in out-of-sample predictions of actual behaviors and (2) result in preference structures that give greater importance to price and may exhibit greater heterogeneity for socially desirable product attributes in the incentive aligned condition.

To test these hypotheses, we conducted two field experiments. The first experiment, Study 1, had four conditions: the conventional (hypothetical) choice conjoint; the conventional (hypothetical) contingent valuation, or stated-price, method; and their corresponding incentivealigned versions. The context we employed was Chinese dinners. Study 2 had two conditions: the conventional (hypothetical) choice conjoint and its corresponding incentive-aligned version 
and used snacks as its context. The results from these experiments demonstrate that conventional conjoint analysis exhibits hypothetical bias and that incentive-aligned choice conjoint significantly improves the out-of-sample predictions of actual purchase behaviors. The structure of partworths and relative importance of various attributes also differ for incentivealigned conditions compared with traditional hypothetical conditions.

\section{STUDY 1: CHINESE DINNER SPECIAL}

To examine the possibility of hypothetical bias, we required a research context that (1) represents a real economic decision for the subject pool (undergraduate and graduate students at a major U.S. university); (2) has a large set of attributes, each with several levels; (3) can generate new products easily through different combinations of the attributes; and (4) provides an easy means to induce realism in the product category due to ease of implementation. Chinese dinner specials meet these four criteria: (1) university students are interested in Chinese food, (2) Chinese dinner specials have a sufficient number of attributes, (3) these attributes can be used to generate product options, and (4) Chinese food can be easily prepared in real time and consumed by the subjects right after the experiment. Therefore, Chinese dinner specials serve as the context for this study.

Qualitative Investigation

We first conducted qualitative investigations to understand the key attributes of Chinese dinner specials. Using an actual menu from the Chinese restaurant in which the experiment was conducted, we interviewed 10 undergraduate students to determine the attributes of a Chinese dinner special that were important to them and that they perceived as important to their peers. We then summarized the results and used them to develop a formal survey, which we gave to two groups of undergraduate marketing students (50 students total) to obtain a better 
understanding of attribute importance and assess the appropriate levels for the attributes. On the basis of the survey, we identified a total of eight important attributes associated with Chinese dinner specials, of which two have two levels, five have three levels, and one has four levels (see Appendix 1).

$\underline{\text { Experimental Design }}$

We developed four different experimental treatments, namely, hypothetical choice conjoint, hypothetical contingent valuation method, incentive-aligned choice conjoint, and incentive-aligned contingent valuation method. Subjects in the hypothetical treatments were not bound by their responses with regard to various tasks, but the subjects in the incentive-aligned treatments were told that they had to live with their choices. (In this case, they were given, through certain random mechanisms, one of the dinner special they selected.)

To manage respondent fatigue, we used, similar to Lazari and Anderson (1994), a fractional factorial design, which generated 108 profiles (Chinese meals). In the choice conditions, we therefore created three groups of 12 choice sets. Each choice set had three profiles (Chinese meals) and a "none of the above" option. We randomly assigned 9 subjects to each of the three groups in the choice conditions (hypothetical and incentive-aligned), resulting in a total of 27 subjects in each of the choice-based treatments. To ensure that the contingent valuation method was based on the profiles used for the choice method, we evenly divided the choice profiles (without the price attribute) into nine groups of 12 profiles. Then, for the hypothetical contingent and incentive-aligned contingent valuation methods, we randomly assigned 3 subjects to each of these nine groups, resulting in a total of 27 subjects in each of the contingent valuation treatments. Because this was a between-subjects design, each subject appeared in only one of the four treatment groups. 
These treatments constitute Part 1 of the experiment; the exact instructions given to the participants are included in Appendix 1. Part 2 of the experiment, which was the same for all subjects, was a holdout task. During the holdout task, each subject chose a meal from a menu of 20 different Chinese dinner specials (none of which appeared in Part 1; see Appendix 2) or chose nothing at all (a total of 21 options). For all of the participants, the choice made during Part 2 was real; that is, the restaurant served the meal they chose, and the cost of the meal was deducted from the $\$ 10$ each participant received for the experiment. For participants in the incentive conditions, a random device was used to determine whether the meal they received came from Part 1 or Part 2 of the study. Finally, Part 3 comprised a brief exit survey that captured information about demographics, prior experience with Chinese food, and whether the subject understood the instructions in Parts 1 and 2.

\section{$\underline{\text { Pilot Experiment }}$}

One of the major reasons conjoint analysis may not perform well is because the respondents are not serious about the purchase at the time of the study but answer the hypothetical questions as if they were. The incentive-aligned methods (incentive-aligned choice conjoint and incentive-aligned contingent valuation method), by definition and unlike the hypothetical methods, will not result in purchase if the subject is not serious about purchasing and will automatically identify those subjects. We conducted a pilot study to understand the existence and scope of such individuals. Specifically, we recruited 41 participants for the hypothetical choice conjoint and used conditions that mirrored the settings common in conjoint studies. The differences between this pilot study and the main study are as follows: (1) The pilot study was conducted in a classroom, whereas the main study was conducted in a restaurant; (2) the pilot study was conducted during regular class time, whereas the main study was conducted 
at dinnertime; (3) the holdout task (Part 2) of the pilot study consisted of four choice tasks similar to those in Part 1, in that one of the four options was randomly chosen and the participant was given a coupon for his or her preferred meal plus the difference between $\$ 10$ and the value of the coupon, whereas in the main study, subjects chose from a menu of 20 specials; (4) subjects received a coupon for a Chinese dinner special to be redeemed at a future date in the pilot study, whereas in the main study, subjects consumed the meal at the end of the experiment; and (5) subjects were not screened in the pilot study, whereas in the main study, while recruiting, we instructed the participants that they should only come if they were interested in eating a Chinese meal.

The results confirmed our assertion. For Part 1 of the pilot study, the hypothetical conjoint portion consisted of 12 choice tasks in which participants chose among four options (three different dinners or none of the above). Every participant selected at least one dinner from the 12 choice sets, and participants chose the "none of the above" option $25 \%$ of the time. For the four choice tasks in Part 2, participants chose among four options (three different dinners or none of the above) and were told that the researchers would randomly select one of these choice tasks and that they would have to buy the chosen meal. In Part 2, just over half (21 of 41) of the participants selected "none of the above" for each of the four choice tasks. Overall, the participants choose the "none of the above" option $67 \%$ of the time. Thus, in Part 1 , the hypothetical condition, the respondents behaved as if they were interested in the Chinese dinner specials by preferring a meal to the "none of the above" option, but they behaved very differently when asked to make a real purchase decision (Part 2).

Although these results provide evidence that the incentive-aligned approach induces different behavior, particularly among participants who are not serious about purchasing the 
product, they do not answer a more important and deeper question: Does an incentive-aligned approach improve the quality of answers even when participants are serious about the purchase decision? Stated differently, even after screening out participants who are not interested in the product (which can constitute a large percentage of subjects used in a typical commercial conjoint study), will the incentive-aligned approaches outperform the traditional approaches with regard to predicting actual purchase behavior, and will they yield substantively different preference structures?

\section{Recruiting Subjects for the Main Experiment}

A recruiting e-mail was sent to a mailing list maintained by the Experimental Economics lab at a large U.S. university. The e-mail stated that participants were needed for a market research experiment to be conducted during dinnertime (5:00-6:00 PM, Monday-Thursday) at a local Chinese restaurant. Participants would have a chance to purchase a Chinese dinner special of their choice during the experiment, which would be cooked by the restaurant and ready for consumption by the end of the experiment. It was explicitly stated in the e-mail that only those interested in eating at this restaurant that evening, provided they could find the right meal at a good price, should participate. Each participant would be paid \$10 for their participation, part of which they could use to purchase a Chinese dinner special. A total of 108 undergraduate and graduate students participated in the main experiment, with an average of 12 students per session. Only 11 of the 108 participants did not choose to buy a meal in the holdout task ( 3 from the incentive-aligned contingent valuation method group, 3 from the incentive-aligned choice conjoint group, and 5 from the hypothetical choice conjoint group). 


\section{Experimental Procedure}

The data collection sessions were scheduled from 5:00-6:00 PM, and the incentivealigned and non-aligned versions (incentive-aligned choice conjoint or incentive-aligned contingent valuation method) were conducted the same day or on successive days to minimize sample variations. Consistent with practices in experimental economics, the experiment was conducted following a written procedure, as described subsequently.

For the hypothetical choice conjoint and hypothetical contingent valuation method, the subjects completed the consent form and Parts 1, 2, and 3 in sequence, and experimenters collected each completed part before the next part was distributed. The restaurant served the meal selected in Part 2. Cash reimbursements ( $\$ 10$ minus the cost of the dinner) were paid upon completion of Part 3. Subjects were dismissed after they were paid, and, similar to the subjects in the two incentive-aligned conditions, most ate the dinner in the restaurant while a few took the dinner home.

The procedure used for the incentive-aligned contingent valuation method treatment is called BDM (Becker, DeGroot, and Marschak 1964). This procedure has been widely used in economics and was recently introduced into marketing to measure willingness to pay at the point of purchase (Wertenbroch and Skiera 2002). In addition to the consent form, subjects were given written instructions that stated they would have two chances of selecting a Chinese dinner special, once in Part 1 and once in Part 2. A random device would be used to decide which selection they would actually receive. Subjects were then given Part 1. After completing Part 1, each subject went through a two-step process in which they chose a dinner special by randomly selecting a number between 1-12 and then randomly drew a piece of paper from an envelope that gave the price for that special (the possible prices ranged from $\$ .25$ to $\$ 8$ in $\$ .25$ increments). 
Following the BDM procedure, if the randomly selected price was equal to or lower than the price stated by a subject, the subject received the dinner special but only had to pay the randomly selected price. The subject did not receive a dinner special if the randomly selected price was higher than the stated price. This procedure ensured that it was in the best interest of the subjects to state their true valuation for a dinner special. After completing Part 1, subjects were given Part 2. After completing Part 2, each subject randomly selected a ball from a container with two balls (labeled Part 1 and Part 2) to decide which dinner choice they would actually consume. Finally, subjects were given Part 3, then given the cash balance ( $\$ 10$ minus the cost of the special) and dismissed after handing in Part 3.

The procedure for incentive-aligned choice conjoint was the same as that for the incentive-aligned contingent valuation method, except that the dinner special chosen in Part 1 was their preferred option from a randomly chosen choice set (which resulted from choosing a random number between 1-12), and they did not need to select a price randomly because they paid the price of the selected dinner. The randomizing mechanism we used to determine which of the participants' choices was fulfilled is called random lottery procedure and is widely used in experimental economics (Starmer and Sugden 1991). This mechanism is used to minimize reference point and wealth effects while allowing investigators to collect a large amount of data. For this study, it also ensures realism, in that a participant is unlikely to eat more than one Chinese meal at a given time in his or her real consumption episode.

\section{Estimation Procedure}

To provide the best possible comparison between the incentive-aligned and hypothetical approaches, we used state-of-art models and estimation methods to assess subjects' preferences, in-sample fit, and out-of-sample predictions. To analyze the rating data (which resulted from the 
stated price and BDM contingent valuation methods), we use a random-effects hierarchical Bayesian regression model, similar to the model specified by Lenk and colleagues (1996). The regression likelihood is as follows:

$$
y_{i t}={ }_{d} N\left(\beta_{i}^{T} x_{i t}, \sigma^{2}\right)
$$

where $y_{i t}$ is the $\mathrm{t}^{\text {th }}$ contingent valuation given by the $\mathrm{i}^{\text {th }}$ subject, $={ }_{d}$ is equal in distribution, $N$ is the normal density, $x_{i t}$ describes the $\mathrm{t}^{\text {th }}$ meal evaluated by the $\mathrm{i}^{\text {th }}$ subject, and $\beta_{i}$ is a vector of contingent valuation partworths for the $i^{\text {th }}$ subject. We assume a hierarchical shrinkage specification for the individual partworths, where a priori,

$$
\beta_{i}={ }_{d} N(\bar{\beta}, \Lambda)
$$

This specification allows for individual-level partworth estimates $\beta_{i}$ but still permits an estimate of the aggregate or average partworths $\bar{\beta}$, as well as an estimate of the amount of heterogeneity for each partworth $\Lambda$. On the basis of in-sample and out-of-sample model performance, we use a simplified version of the model by assuming that $\Lambda$ is a diagonal matrix ${ }^{\text {B }}$ Furthermore, we assume vague conjugate priors for $\bar{\beta}, \Lambda$, and $\sigma^{2}$.

To analyze the choice data, we use a random effects hierarchical Bayesian multinomial logit model ${ }^{\text {I }}$, similar to the model specified by Allenby, Arora, and Ginter (1998). The probability that the $\mathrm{i}^{\text {th }}$ subject chooses the $\mathrm{j}^{\text {th }}$ alternative from the $\mathrm{t}^{\text {th }}$ choice set is given by

$$
\operatorname{Pr}\left(y_{i t}=j\right)=\frac{\exp \left\{\tilde{\beta}_{i}^{T} x_{i t j}\right\}}{\sum_{\ell} \exp \left\{\tilde{\beta}_{i}^{T} x_{i t \ell}\right\}}
$$

\footnotetext{
${ }^{3}$ We considered both a diagonal and a full matrix version of each model and found that the in-sample fit criteria (Bayes factors) moderately supported a full matrix version of the model but that the out-of-sample predictive performance favored a diagonal matrix version of the model.

${ }^{4}$ As pointed out by one of the reviewers the Sawtooth's hierarchical Bayesian software implements a model that is similar to the model that we implemented, which allows other researchers ready access to this model.
} 
Again, we assume a hierarchical shrinkage specification for the individual partworths, where a priori,

$$
\widetilde{\beta}_{i}={ }_{d} N(\overline{\tilde{\beta}}, \tilde{\Lambda})
$$

As with the regression model, we are able to estimate individual-level partworth parameters, average partworth parameters, and the partworth heterogeneity. Again, on the basis of in-sample and out-of-sample model performance, we assume that $\tilde{\Lambda}$ is a diagonal matrix. ${ }^{\xi}$ Furthermore, we assume vague conjugate priors for $\overline{\widetilde{\beta}}$ and $\tilde{\Lambda}$. (Note that, unlike the choice partworth parameters $\overline{\widetilde{\beta}}$, the contingent valuation partworth parameters $\bar{\beta}$ do not have a price sensitivity element, because the contingent valuation is given in terms of the price that the subject is willing to pay for the proposed product.)

We tested a range of different prior values to ensure that the reported results were invariant to the prior specification. In addition, we assessed the convergence properties of the Markov Chain Monte Carlo (MCMC) analysis to ensure that the algorithm had converged to the target density, as induced by the model specification, before making marginal summaries of the posterior density.

$\underline{\text { Results }}$

We assess in-sample goodness of fit for the logit models by calculating the percentage of times the model accurately identified the choice from the four alternatives (the hit rate), among which one alternative was "none of the above." In addition, we estimate the marginal probability of the data given a model (reported on a log scale) using the estimation method provided by Newton and Raftery (1994), which can be used to form Bayes factors. Using the logit model, the

\footnotetext{
${ }^{5}$ As with the regression model, we considered both a diagonal and a full matrix version of each model. For the choice models, we found that both the in-sample fit criteria (Bayes factors) and the predictive performance criteria favored a diagonal matrix version of the model
} 
hypothetical choice conjoint resulted in a better in-sample fit than that of the incentive-aligned choice conjoint (i.e., a hit rate of $32 \%$ and $41 \%$ for the incentive-aligned choice conjoint and hypothetical choice conjoint, respectively). We obtained log-marginal probability values of 1109 and -788 for incentive-aligned choice conjoint and hypothetical choice conjoint respectively. The R-square values of .97 and .96 for incentive-aligned contingent valuation conjoint and hypothetical contingent valuation conjoint respectively, show good overall model fit (the log-marginal probability values for incentive-aligned contingent valuation conjoint and hypothetical contingent valuation conjoint were -401 and -368 respectively).

The incentive-aligned data result in significantly better out-of-sample predictions compared with the hypothetical results, which supports our primary hypothesis (see Figure 1). The incentive-aligned choice conjoint forecasts the correct purchase $48 \%$ of the time, which represents a more-than-tenfold improvement over the naïve forecast rate of around 5\% and is almost twice as good as the hypothetical choice conjoint forecast, which was correct $26 \%$ of the time. The results for the top two choices are equally impressive, with $59 \%$ and $26 \%$ correct predictions in the incentive-aligned choice and hypothetical choice conditions, respectively. The incentive-aligned contingent valuation method analysis results in better out-of-sample forecasts than the hypothetical contingent valuation method, with $15 \%$ compared with $7 \%$ correct. $^{\square^{-}}$These out-of-sample numbers along with the naïve baseline predictions are plotted in Figure 1. The superior out-of-sample predictive performance of incentive-aligned methods is evident from

\footnotetext{
${ }^{6}$ The in-sample fit criteria are only reported for completeness and are based on the same model applied to different data sets. Please note that this approach differs from existing literature, where such comparison is usually done between different models applied to the same data set.

${ }^{7}$ These results seem comparable to previous research that has used actual purchase decisions as validation. For example, for natural experiments involving MBA job choices, Wittink and Montgomery (1979), Srinivasan (1988), and Srinivasan and Park (1997) find that the first preference predictions range from 64\% to 76\%, compared with random choice results of $26 \%$ to $36 \%$. Similarly, Dahan and colleagues (2002) report a 50\% to 59\% correct predictive performance for five new-to-market laptop computer bags, compared with a random choice outcome of $20 \%$. With incentive-aligned choice conjoint, the predictions were correct $48 \%$ of the time compared with the random choice outcome of less than 5\% (1 of 21).
} 
Figure 1. Figure 1 also provides support for the superior performance of choice methods when compared with contingent valuation methods. We discuss several possible explanations for this result in favor of the choice methods in the next section.

\section{[Insert Figure 1 Here]}

In addition to resulting in better out-of-sample forecasts, the aggregate parameter estimates based on the incentive-aligned tasks are markedly different from the estimates of the non-incentive-aligned tasks (see Table 1$){ }^{8}$ Perhaps the most striking finding is that, on average, the participants from the incentive-aligned task are more price sensitive $(-1.59)$ than are those from the non-incentive-aligned task (-.99), and their price sensitivity is spread over a larger range, as indicated by the difference in the heterogeneity of the slopes (.44 and .20 for the incentive-aligned and non-incentive-aligned, respectively). This finding is consistent with a notion in experimental economics literature, which suggests that subjects may discount budget constraints in hypothetical conditions (Diamond and Hausman 1994; List 2001). In addition, the average importance of the size of the meal, given by the Quart partworth, is almost three standard deviations above zero $(2.8=1.29 / .46)$ for participants in the hypothetical conjoint task and just over one standard deviation above zero $(1.03=.40 / .39)$ for the incentive-aligned task, which indicates that, when the task is incentive aligned, the effect of the size of the meal becomes negligible. One explanation is that, though the additional quantity warrants higher valuation in theory, subjects may less likely to associate it with similarly high valuation in a real purchase experience because they know they are unlikely to eat that additional amount (or if they do, that it will not do them any good).

\footnotetext{
${ }^{8}$ Because the choice models result in much better out-of-sample predictive ability, we focus our discussion on the difference between the parameter estimates from these analyses. We include the contingent valuation results to be consistent with the practice in experimental economics of reporting all study results.
} 
Another interesting insight is that the levels of individual heterogeneity, as given by the diagonal elements of $\Lambda$ and $\tilde{\Lambda}$, are markedly different for the incentive and hypothetical treatments. Consistent with assertions in experimental economics literature (e.g., Camerer and Hogarth 1999), the heterogeneity for socially desirable alternatives should increase when subjects are presented with a real decision as opposed to a hypothetical decision. For example, consider the heterogeneity of the partworths for chicken and shrimp (which may be considered healthier alternatives to beef). The heterogeneity of the partworths of chicken and shrimp is smaller for the hypothetical choice conjoint than the incentive-aligned choice conjoint..$^{0}$ This result may suggest that, in the hypothetical setting, some subjects conform to the social norm of selecting healthy alternatives, whereas many subjects who followed this norm in the hypothetical setting are likely to abandon it in the incentive-aligned setting because they have to live with (or, in this case, eat) their choice, thereby increasing the heterogeneity in the incentive-aligned condition. However, we do observe similar shift in heterogeneity of beef, even though the magnitude of the change in heterogeneity is much smaller (the magnitude of change in heterogeneity of beef is around .3 compared with 3.5 for Chicken and .9 for Shrimp). Nonetheless, these notions on social desirability need further exploration.

Further, the heterogeneity for exotic vegetables (a riskier option compared with standard vegetables) reduces from 3.84 for hypothetical choice conjoint to 2.99 for incentive-aligned choice conjoint. This decrease in heterogeneity is accompanied by a decrease in the average

\footnotetext{
${ }^{9}$ With an independent sample of respondents from the same population as the Study 1, we collected data on the social desirability of chicken, shrimp, and beef. Specifically, for each attribute, the respondents answered the following three questions on a 1-7 agree-disagree scale: (1) I think it is socially desirable to eat beef, (2) my friends and family would agree that it is socially desirable to consume beef, and (3) there is a general perception that consuming beef is socially desirable. Because the Cronbach's $\alpha$ for the three scales exceeded .84, we averaged the three items to construct social desirability measures for chicken, shrimp, and beef. Paired sample t-tests showed that, for the 37 respondents, eating chicken was more socially desirable than beef $(\mathrm{t}=2.91, p<.01)$, eating shrimp was more socially desirable than beef $(\mathrm{t}=2.12, p<.05)$, and there was no difference in the social desirability of chicken and shrimp $(\mathrm{t}=-.63, p>.53)$. The results thus show that chicken and shrimp are more socially desirable among the subject population than is beef.
} 
partworth weight from 1.00 in hypothetical choice conjoint to .23 in incentive-aligned choice conjoint. Some subjects in the hypothetical choice conjoint may have chosen exotic vegetables to try new items, but in the incentive-aligned choice conjoint, the subjects seem to be more risk averse and do not prefer the novel exotic vegetable attribute. Similar insights hold for the regression-based parameter estimates (see Table 2).

\section{[Insert Tables $1 \& 2$ Here]}

According to the pilot study, it is almost certain that, had we not screened out subjects who were not serious about the purchase decision, the incentive-aligned contingent valuation method would have performed better than the hypothetical contingent valuation method and that the incentive-aligned choice conjoint would have performed better than the hypothetical choice conjoint. It is very informative that the incentive-aligned methods outperform their hypothetical counterparts, even after participants who are not serious about purchase have been excluded from the study. This result suggests that it is very important to find ways of using incentives that are aligned with purchase behavior in conjoint studies.

\section{STUDY 2: SNACK COMBO}

To test the robustness of the Study 1 findings, especially the strong increase in out-ofsample forecasting accuracy, we conducted a second study that focused on the choice conjoint. The task context for this second study was a snack combo. Specifically, subjects identified their

preferences for a snack combo that could have one (or none) of the following four attributes: a drink (water, coca cola, diet coke, iced tea, or orange juice), a cookie (peanut butter, chocolate fudge, or oatmeal raisin), a Korean cereal bar (white, dark, or strawberry chocolate), and a piece 
of fruit (banana or apple). Each snack combo was priced at one of three levels $(\$ 1.00, \$ 1.75$, or \$2.50).

We chose the snack combo context because, similar to Study 1, a snack combo is a familiar context for our subjects and we could choose multiple levels easily for each attribute. However, the snack combo context is appealing also because it differs from the Chinese dinner special context in several ways. First, because the attributes in the snack combo are different snack categories (e.g., cookies and fruit), they are less likely to interact with one another than the attributes in the Chinese dinner special (e.g., the value of a particular sauce is likely to interact with a specific meat or vegetable). Second, there is neither uncertainty nor inconsistency with regard to the product quality in Study 2. The quality of the Chinese dinner special depended on the restaurant and the cook, which added to the uncertainty of the conjoint study and the holdout task in Study 1. In contrast, the snack combo consisted of items that could be bought at a grocery store and, except for the fruit, were prepackaged, brand-name products.

To assess the robustness of the results, we changed the study design in several ways. First, we included an unfamiliar attribute: the Korean cereal bar. With this attribute, we can test risk preference and willingness to try new things explicitly. Second, we used an orthogonal design to generate a total of 27 conjoint tasks (each task had four choices, three snack combos or none of the above), which enabled us to ask every subject to complete all 27 tasks, whereas in Study 1 , we divided the total tasks into three groups, and each subject only evaluated one-third of the profiles. Therefore, in Study 1, we needed to pool information across subjects to obtain the parameter estimates. Third, we divided the subjects into two sessions. Although the experiments for each session were the same, the 30 snack combos in the holdout task appeared in different sequences to minimize the impact of any potential order effects. 


\section{$\underline{\text { Experiment }}$}

We visited stores and cafés frequented by the subject pool to identify popular brands of drinks and cookies and obtain reasonable price levels. To ensure that our Study 1 risk preference results could be generalized to a context in which the attributes were completely new to the subjects (in contrast to the exotic vegetables in Study 1), we visited a local Oriental-foods store and chose three varieties of a Korean cereal bar. According to the store owner, the bar had just been introduced to the local market and was not available in mainstream channels (e.g., chain grocery store, which we verified). We used the built-in routine in SPSS to generate 27 conjoint tasks (with three snack combo profiles in each task, for a total of 81 different snack combos) and another 30 unique snack combos for the holdout task.

We recruited 59 senior undergraduate students from the same U.S. university as in Study 1. The experiment was conducted over two sessions, and subjects in each session were randomly assigned to either the incentive-aligned choice conjoint or the hypothetical choice conjoint. Snacks were brought into the room before the start of each session; food items in each snack combo were packaged in a large freezer bag, and the drinks were stored in a cooler with ice. Subjects knew precisely the brand and quality of snack they might buy.

The experimental procedure for both the incentive-aligned and hypothetical choice conjoint conditions was similar to Study 1 (Appendix 3). After completing the conjoint task, all subjects were given instruction for the holdout task (Appendix 4), in which they selected 1 of the 30 possible snack combos or no snack combo. The subjects in the hypothetical choice conjoint condition received $\$ 3$, out of which they could buy any of the 30 snack combos in the holdout task. The subjects in the incentive-aligned choice conjoint condition were also given $\$ 3$ and had two opportunities to buy a snack combo, one in the conjoint task (selected using a random 
lottery, as in Study 1) and one in the holdout task. One of the opportunities was randomly selected for each subject, and his or her choice was then fulfilled. At the completion of the experiment, the subjects were given the snack combo of their choice and received the balance of $\$ 3$ less the price of the snack combo they chose.

\section{$\underline{\text { Results }}$}

Using the same estimation approach, in terms of in-sample hit rate and log-marginal

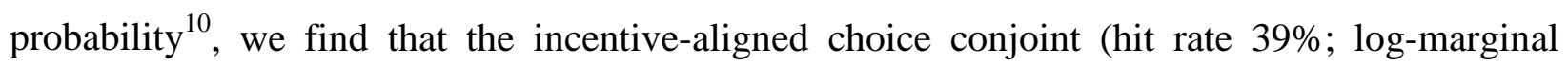
probability -2619) outperforms the hypothetical choice conjoint (hit rate 32\%; log-marginal probability -2795) condition for the snacks data set, in contrast to the in-sample results in Study 1. For out-of-sample predictions, the incentive-aligned choice conjoint (top choice 18\%; top two choices 36\%) also outperforms the hypothetical choice conjoint (top choice 13\%; top two choices $16 \%$ ) condition, in support of our hypothesis that incentive-aligned conjoint will predict actual purchase behavior better than hypothetical conjoint. In Figure 2 we plot these out-ofsample predictive performance of incentive-aligned choice conjoint and hypothetical choice conjoint relative to the naïve baseline prediction (i.e., 1 in 31 for top choice and 2 in 31 for top two choices). This figure confirms the findings of Study 1 that incentive-aligned choice conjoint is far superior to its hypothetical counterpart.

\section{[Insert Figure 2 Here]}

Similar to Study 1, we find markedly different aggregate parameter estimates for incentive-aligned and hypothetical tasks. Subjects are more price sensitive in the incentivealigned condition (-4.18) than in the hypothetical condition (-2.61). Price heterogeneity appears much higher in the incentive-aligned condition (5.60) than in the hypothetical condition (.90).

\footnotetext{
${ }^{10}$ Again, the in-sample fit criteria are only reported for completeness and are based on the same model applied to different data sets. Please note this is different from the existing literature, which usually compares different models applied to the same data set.
} 
Similarly, as we show in Table 3, the slope and heterogeneity parameters differ for other attribute-level combinations. For the novel attribute (i.e., Korean cereal bars), we find lower slope and heterogeneity in the incentive-aligned condition than in the hypothetical condition. These results suggest that, in a hypothetical setting, subjects tend to overstate their levels of risk preference and willingness to try new things compared with when they are in a real purchasing environment. Indeed, this conjecture concerning risk preferences and other conjectures concerning social desirability bias do merit further scrutiny.

\section{[Insert Table 3 Here] \\ GENERAL DISCUSSION}

We rely on the literature of induced value theory (Smith 1976) and hypothetical bias (Diamond and Hausman 1994) to suggest that contemporary conjoint-based methods may poorly identify consumer preference. Specifically, traditional conjoint techniques deal with hypothetical situations, and experimental economics literature suggests that a hypothetical setting does not motivate subjects sufficiently to reveal their "true" preferences. We propose overcoming this weakness with incentive-aligned conjoint methods, specifically, using incentivealigned versions of choice-based conjoint and the contingent valuation method.

Our results across the two studies provide strong evidence in favor of the incentivealigned choice conjoint in terms of out-of-sample predictions of purchase decisions. We also find that subjects in the incentive-aligned choice conjoint condition have systematically different preference structures than do subjects in other conditions. Most notably, the subjects in the incentive-aligned choice conjoint condition, compared with those in hypothetical condition, have higher price sensitivity, exhibit lower risk seeking and willingness to try new things, and are less prone to socially desirable behaviors. 
The benefits of incentive-aligned conditions for marketing researchers are evident and substantial. Marketing researchers should use incentive-aligned conjoint, and marketing academics should study incentive-aligned conjoint further to better understand the linkages between stated (hypothetical) and revealed (incentive-aligned) preferences.

The strong findings across both studies in favor of incentive alignment for individual decision making suggests that marketing academics should also investigate incentive alignment for both group decision making ${ }^{1}$ in consumer markets for which group norms can play an important role (e.g., family decision making) and organizational decision making in business markets. Furthermore, academics should explore whether using hypothetical and incentivealigned conditions in combination improves out-of-sample predictions. For example, a conceivable research design could involve three stages: (1) hypothetical conjoint, (2) incentivealigned conjoint, and (3) a holdout task. $\frac{12}{}$ In addition to providing potential prediction benefits, such a research design may suggest the manner in which subjects change their preferences. Comparative studies with process measures for both hypothetical and incentive conditions could illuminate the differences in the decision-making tasks in the two conditions.

From a managerial perspective, the most relevant issue is to identify and test various implementation strategies that align subjects' incentives for a wide range of products. We believe the basic guidelines can be implemented for various product categories, especially when the attributes are well understood and the product can be made available. However, a serious implementation challenge remains for expensive or complex products (e.g., automobiles) and for novel products for which a prototype may not even exist. In the case of expensive products, it

\footnotetext{
${ }^{11}$ In both studies, we attempted to ensure that the experiments focused on individual decision making. In neither study were the participants allowed to communicate and or see one another's; in the Chinese dinner study, participants who arrived in a group were required to sit at different tables.

${ }^{12}$ We thank an anonymous $J M R$ reviewer for this suggestion.
} 
may not be cost effective to offer a real product to each subject. Market researchers therefore must ensure that the potential earning is greater than the subjects' opportunity cost. For example, an automobile company interested in an incentive-aligned conjoint study only needs to offer one or two automobiles to one or two randomly selected subjects, as long as the potential earning (value of the car times the likelihood of winning) is greater than each subject's opportunity cost. Key to this lottery approach, however, is that the winning subject must receive the car that matches his or her stated preference in the study. Another challenge is to obtain a sample that is interested in the product at the time of the exercise. By recruiting only subjects who self-select (as we did in the Chinese dinner special context) as being interested in the product at the time of the exercise, this challenge may be met. In addition, to help eliminate participants who are only interested in monetary payments, part of the compensation should be the product, rather than cash.

For novel products, incentive alignment can be truly difficult, as can other issues such as forecasting. Borrowing a page from Urban and colleagues (1997), virtual representations, such as information acceleration, might enable researchers to collect data (though hypothetical) on new product concepts. By tabulating the necessary adjustments to make hypothetical conjoint consistent with incentive-aligned conjoint for various existing product categories, researchers could then carry out hypothetical conjoint exercises and adjust the preference structure using product(s) similar to the new product. Thus, calibrating hypothetical conjoint with incentivealigned conjoint becomes a critical research question.

In conclusion, for managers, the guiding principle is simply to align respondents' interests to the actual decision outcome and ensure that the incentive is not trivial with regard to their opportunity cost. For example, the subject might receive a coupon redeemable only for the 
preferred choice he or she made during the study. As is apparent by the Noble Prize given to Vernon Smith for his pioneering work in experimental economics and as our results demonstrate, the ability of incentive alignment to improve conjoint analysis is great. Our research suggests that marketing researchers should use incentive alignment to assess consumer preferences and continue to conduct further research in the context of conjoint and other experiments that pertain to consumer behavior. 


\section{REFERENCES}

Allenby, Greg M., Neeraj Arora, and James L. Ginter (1998), "On the Heterogeneity of Demand," Journal of Marketing Research, 35 (3), 384-389.

Becker, Gordon M., Morris H. DeGroot, and Jacob Marschak (1964), "Measuring Utility by a Single-Response Sequential Method," Behavioral Science, 9 (July), 226-232.

Bishop, R. and T.A. Heberlein (1986), “Does Contingent Valuation Work?" in Valuing Environmental Goods: A State of the Arts Assessment of Contingent Valuation Method, R. Cummings, D. Brookshire, and W. Schulze, eds. Totowa, NJ: Rowman \& Allenheld.

Camerer, Colin F. and Robin M. Hogarth (1999), "The Effects of Financial Incentives in Experiments: A Review and Capital-Labor-Production Framework," Journal of Risk and Uncertainty, 19 (1-3), 7-42.

Carroll, J. Douglas and Paul E. Green (1995), "Psychometric Methods in Marketing Research: Part I, Conjoint Analysis,” Journal of Marketing Research, 32 (4), 385-391.

Cattin, Philippe and Dick R. Wittink (1982), "Commercial Use of Conjoint Analysis: A Survey," Journal of Marketing, 46 (3), 44-53.

Dahan, E., J.R. Hauser, D. Simester, and O. Toubia (2002), “Application and Test of Web-Based Adaptive Polyhedral Conjoint Analysis," Working Paper Number 146, Center for eBusiness@MIT

Diamond, P.A. and J.A. Hausman (1994), "Contingent Valuation: Is Some Number Better than No Number?” Journal of Economic Perspectives, 8 (4), 45-64.

Davidson, J.D. (1973), "Forecasting Traffic on STOL," Operations Research Quarterly, 22, 561569.

Elrod, Terry, Jordan J. Louviere, and Krishnakumar S. Davey (1992), "An Empirical Comparison of Rating-Based and Choice-Based Conjoint Models," Journal of Marketing Research, 29 (August), 368-377.

Green, Paul E., Kristiaan Helsen, and Bruce Shandler (1988), "Conjoint Validity under Alternative Profile Presentation," Journal of Consumer Research, 15 (December), 392-397.

and Abba M. Krieger (1991), "Segmenting Markets with Conjoint Analysis," Journal of Marketing, 55 (4), 20-31.

and - (1992), "An Application of Product Positioning Model to Pharmaceutical Products," Marketing Science, 11 (2), 117-132.

$\longrightarrow, \ldots$, and Yoram Wind (2001), "Thirty Years of Conjoint Analysis: Reflections and Prospects," Interfaces, 31 (3), S56-S73. 
and V. Srinivasan (1978), "Conjoint Analysis in Consumer Research: Issues and Outlook," Journal of Consumer Research, 5 (September), 103-123.

and - (1990), "Conjoint Analysis in Marketing: New Developments with Implications for Research and Practice,” Journal of Marketing, 54 (October), 3-19.

Johnson, Eric, Robert J. Meyer, and Sanjay Ghose (1989), "When Choice Models Fail: Compensatory Models in Negatively Correlated Environments," Journal of Marketing Research, 26 (August), 255-270.

Kohli, Rajiv and Vijay Mahajan (1991), "A Reservation-Price Model for Optimal Pricing of Multiattribute Products in Conjoint Analysis," Journal of Marketing Research, 28 (3), 347-354.

Lazari, Andreas G. and Donald A. Anderson (1994), "Designs of Discrete Choice Set Experiments for Estimating Both Attribute and Availability Cross Effects," Journal of Marketing Research, 31 (August), 375-83.

Leigh, Thomas W., David B. MacKay, and John O. Summers (1984), "Reliability and Validity in Conjoint Analysis and Self-Explicated Weights: A Comparison," Journal of Marketing Research, 21 (November), 456-462.

Lenk, Peter J., Wayne S. DeSarbo, Paul E. Green, and Martin R. Young (1996), "Hierarchical Bayes Conjoint Analysis: Recovery of Partworth Heterogeneity from Reduced Experimental Designs," Marketing Science, 15 (2), 173-191.

List, J.A. (2001), "Do Explicit Warnings Eliminate the Hypothetical Bias in Elicitation Procedures? Evidence from Field Auctions for Sportscards," American Economic Review, 91 (5), 1498-1507.

List, J.A. and J.F. Shogren (1998), “The Deadweight Loss of Christmas: Comment," American Economic Review, 88 (5), 1350-55.

Mahajan, V., P.E. Green, and S.M. Goldberg (1982), "A Conjoint Model for Measuring Selfand Cross-Price/Demand Relationships," Journal of Marketing Research, 19 (3), 334-342.

Newton, Michael A. and Adrian E. Raftery (1994), "Approximate Bayesian Inference by the Weighted Likelihood Bootstrap (with Discussion)," Journal of the Royal Statistical Society, Series B, 56, 3-48.

Page, Albert L. and Harold F. Rosenbaum (1987), "Redesigning Product Lines with Conjoint Analysis: How Sunbeam Does It," Journal of Product Innovation Management, 4 (2), 120-137.

Robinson, Patrick J. (1980), "Application of Conjoint Analysis to Pricing Problems," in Proceedings of the First ORSA/TIMS Special Interest Conference on Marketing Measurement 
and Analysis, D.B. Montgomery and D.R. Wittink, eds., Cambridge MA: Marketing Science Institute 183-205.

Smith, Vernon L. (1976), "Experimental Economics: Induced Value Theory," American Economic Review, 66 (2), 274-79.

and James M. Walker (1993), "Monetary Rewards and Decision Cost in Experimental Economics,” Economic-Inquiry, 31 (2), 245-61.

Srinivasan, V. (1988), "A Conjunctive-Compensatory Approach to the Self-Explication of Multiattributed Preferences," Decision Sciences, 19 (2), 295-305.

—, Peter G. Flaschsbart, Jarir S. Dajani, and Rolfe G. Hartley (1981), "Forecasting the Effectiveness of Work-Trip Gasoline Conservation Policies Through Conjoint Analysis," Journal of Marketing, 45 (Summer), 157-172.

and C.S. Park (1997), "Surprising Robustness of Self-Explicated Approach to Customer Preference Structure Measurement,” Journal of Marketing Research, 34 (May), 286-291.

Starmer, C. and R. Sugden (1991), "Does the Random-Lottery Incentive System Elicit True Preferences? An Experimental Investigation," American Economic Review, 81 (4), 971-978.

Urban, Glen L., John R. Hauser, William J. Qualls, Bruce D. Weinberg, Jonathan D. Bohlmann, and Roberta A. Chicos (1997), "Validation and Lessons from the Field: Applications of Information Acceleration," Journal of Marketing Research, 34 (February), 143-153.

Wertenbroch, Klaus and Bernd Skiera (2002), "Measuring Consumers' Willingness to Pay at the Point of Purchase," Journal of Marketing Research, 39 (2), 228-241.

Wittink, Dick R. and Philippe Cattin (1989), "Commercial Use of Conjoint Analysis: An Update," Journal of Marketing, 53 (July), 91-96.

and David B. Montgomery (1979), "Predictive Validity of Trade-Off Analysis for Alternative Segmentation Schemes," in Educators' Conference Proceedings, Series 44, Neil Beckwith et al., eds. Chicago: American Marketing Association, 69-73.

—, Marco Vriens, and Wim Burhenne (1994), "Commercial Use of Conjoint Analysis in Europe: Results and Critical Reflections," International Journal of Research in Marketing, 11 (1), 41-52.

Wright, Peter and Mary Ann Kriewall (1980), "State-of-Mind Effects on the Accuracy with which Utility Function Predicts Marketplace Choice," Journal of Marketing Research, 17 (August), 277-293. 


\section{APPENDIX 1: EXPERIMENT INSTRUCTION FOR STUDY 1 (PART 1)}

In this Appendix, we provide the exact instructions for the experiment conducted in Study 1. Each subject read the GENERAL INSTRUCTION first, followed by SPECIFIC INSTRUCTIONS for the experimental condition to which he or she was assigned. We also include one conjoint task example and one contingent valuation task example.

\section{GENERAL INSTRUCTION (for all experimental conditions)}

You are about to participate in an experiment designed to understand how people like you value a variety of different Chinese meals (Dinner Specials). We would ask that you pay close attention to the different meals being offered and determine an accurate value for each meal.

You will receive $\$ 10$ for participating in this experiment.

Before proceeding with the remainder of the study, we would like to familiarize you with the type of meals that you will be considering. Each Dinner Special will be described by 8 attributes: (During the course of the study, you may wish to refer to the following table).

\begin{tabular}{|c|c|c|c|c|}
\hline Attribute & \multicolumn{4}{|c|}{ Levels } \\
\hline Soup & No Soup & \multicolumn{2}{|c|}{ Hot \& Sour Soup } & Egg Drop Soup \\
\hline Rice/Noodle & White Rice & \multicolumn{2}{|c|}{ Brown Rice } & Noodles \\
\hline Sauce & Brown Sauce & \multicolumn{2}{|c|}{$\begin{array}{l}\text { Szechwan Sauce } \\
\text { (Hot and Spicy) }\end{array}$} & Sweet and Sour Sauce \\
\hline Vegetables & No Vegetables & \multicolumn{2}{|c|}{ Standard Vegetables ${ }^{*}$} & $\begin{array}{l}\text { Tofu \& Exotic } \\
\text { Vegetables }\end{array}$ \\
\hline Meat & No Meat & Beef & Chicken & Shrimp \\
\hline Spring Roll & \multicolumn{2}{|c|}{ Vegetable Spring Roll } & \multicolumn{2}{|c|}{ Pork Spring Roll } \\
\hline Quantity & \multicolumn{2}{|c|}{ Pint } & \multicolumn{2}{|c|}{ Quart (2 Pints) } \\
\hline Price & $\$ 3.99$ & \multicolumn{2}{|c|}{$\$ 4.99$} & $\$ 5.99$ \\
\hline
\end{tabular}

*Standard Vegetables: (Includes common vegetables that you would find in a supermarket, e.g. broccoli, green peppers, green beans, mushrooms, snow peas, etc.).

**Exotic Vegetables: (Includes vegetables usually found in Asia, e.g., bamboo shoots, Shanghai Bokchoy, Green Mustard, Chinese egg, among others).

\section{$\underline{\text { SPECIFIC INSTRUCTIONS }}$}

\section{Non-Incentive-Aligned Conjoint}

You will be shown twelve sets of three meals. For each set of three meals, imagine that you were asked to choose between no meal and one of these three different meals at the stated price. Select the most attractive option (which could include not selecting any of the meals). 


\section{Incentive-Aligned Conjoint}

You now have an opportunity to select a Chinese Dinner Special and have it cooked here in the restaurant before you leave. Here is how it works. You will be shown twelve sets of three meals. For each set of three meals, please choose between no meal and one of these three different meals at the stated price (which could include not selecting any of the meals). After you complete your selection, we will randomly choose a set from these twelve sets, and your choice for that set will be fulfilled. If you have selected no meal for that set, you will be given $\$ 10$ cash to take home; if you have selected a meal for that set, the restaurant will cook that meal for you, and you will be given $\$ 10$ minus the price of that meal as stated.

\section{An Example of the Conjoint Task}

\section{Choice Set 1}

\begin{tabular}{|c|}
\hline Attributes \\
\hline Soup \\
\hline Rice/Noodle \\
\hline Sauce \\
\hline Vegetables \\
\hline Meat \\
\hline Spring Roll \\
\hline Quantity \\
\hline Price \\
\hline
\end{tabular}

\begin{tabular}{|c|}
\hline Meal 1 \\
\hline Hot \& Sour \\
\hline Noodles \\
\hline Brown Sauce \\
\hline No Vegetables \\
\hline No Meat \\
\hline Vegetable \\
\hline Pint \\
\hline$\$ 3.99$ \\
\hline
\end{tabular}

\begin{tabular}{|c|}
\hline Meal 2 \\
\hline Hot \& Sour \\
\hline White Rice \\
\hline Szechwan \\
Sauce \\
\hline Standard \\
Vegetables \\
\hline Beef \\
\hline Pork \\
\hline Pint \\
\hline$\$ 5.99$ \\
\hline
\end{tabular}

\begin{tabular}{|c|}
\hline Meal 3 \\
\hline Hot \& Sour \\
\hline Brown Rice \\
\hline $\begin{array}{c}\text { Sweet and Sour } \\
\text { Sauce }\end{array}$ \\
\hline $\begin{array}{c}\text { Tofu \& Exotic } \\
\text { Vegetables }\end{array}$ \\
\hline Chicken \\
\hline Pork \\
\hline Quart \\
\hline \$5.99 \\
\hline
\end{tabular}

Please indicate which meal you would choose (circle your choice).

- Meal 1

- Meal 2

- Meal 3

- None of the Above

\section{$\underline{\text { Non-Incentive-Aligned Contingent Valuation }}$}

You will be shown twelve different meals. For each meal, imagine that you were to state the price you would be willing to pay for the meal, and then write down the price for the meal.

\section{$\underline{\text { Incentive-Aligned Contingent Valuation (BDM Procedure) }}$}

You will be presented with twelve meals in this part of the experiment; please tell us the highest price you would be willing to pay for each meal. After you state your maximum prices for all twelve meals, we will determine which meal you will actually buy and how much you will pay for it based on the following procedure. 
First, you will be asked to draw a ball from an envelope, which contains 12 balls labeled 1-12. You will be able to purchase the meal that has the same number as the one written on the ball.

Next, you will be asked to draw a ball/ticket from another envelope. The balls/tickets are labeled with different prices; the range of these prices is reasonable for a Chinese Dinner Special, neither too high nor too low. If you draw a price that is less than or equal to the price you choose for that meal, you will have to buy the Special for the price you drew from the envelope. If the price you draw is greater than the price you choose, you will not be able to buy that particular meal. This procedure ensures that it is best for you to truthfully reveal the maximum price you are willing to pay for each meal. If you choose a price that is high, you may actually have to pay that high price. If you choose a price that is low, you may be disappointed if you can't buy the meal at the low price because you drew a price that is higher than the price you choose but lower than your "true" price. Note that you cannot influence the purchase price with the price you choose. Because you draw the purchase price from the envelope, it is completely random and independent of whatever you choose. For example, if you state your maximum price for Meal 3 is $\$ 7.24$, and you draw a price of $\$ 2.30$, you will receive Meal 3 for $\$ 2.30$, and receive remaining the $\$ 7.70(\$ 10-\$ 2.30)$ in cash.

\section{An Example of the Contingent Valuation Task}

\section{Meal 1}

\begin{tabular}{|c|}
\hline Attributes \\
\hline Soup \\
\hline Rice/Noodle \\
\hline Sauce \\
\hline Vegetables \\
\hline Meat \\
\hline Spring Roll \\
\hline Quantity \\
\hline
\end{tabular}

\begin{tabular}{|c|}
\hline Description \\
\hline Egg Drop \\
\hline Noodles \\
\hline Brown Sauce \\
\hline Tofu \& Exotic Vegetables \\
\hline Beef \\
\hline Vegetable \\
\hline Pint \\
\hline
\end{tabular}

Please indicate how much you would be willing to pay for the above meal $\$$ 


\section{APPENDIX 2: HOLDOUT TASK FOR STUDY 1 (PART 2)}

Now you have to choose a single meal out of the twenty possible dinner specials presented in this part of the experiment. You may choose to select none of the twenty meals and thereby elect not to purchase. If you choose a meal, you will have to pay for it. For example, if

you select to purchase the $3^{\text {rd }}$ Dinner Special Meal at $\$ 4.99$, we will give you $\$ 5.01(\$ 10-\$ 4.99)$ in cash, and the restaurant will cook that meal for you while you wait.

Please examine the meals on the next two pages and indicate your choice below:

Choose Meal No

Do not wish to purchase any of the 20 Dinner Specials 
Description of Possible Meals

\begin{tabular}{|c|c|c|c|c|c|c|c|c|c|c|}
\hline Attributes & Meal 1 & Meal 2 & Meal 3 & Meal 4 & Meal 5 & Meal 6 & Meal 7 & Meal 8 & Meal 9 & Meal 10 \\
\hline Soup & None & $\begin{array}{l}\text { Hot \& Sour } \\
\text { Soup }\end{array}$ & $\begin{array}{l}\text { Egg Drop } \\
\text { Soup }\end{array}$ & None & $\begin{array}{l}\text { Hot \& Sour } \\
\text { Soup }\end{array}$ & None & None & $\begin{array}{l}\text { Egg Drop } \\
\text { Soup }\end{array}$ & $\begin{array}{l}\text { Hot \& Sour } \\
\text { Soup }\end{array}$ & $\begin{array}{l}\text { Egg Drop } \\
\text { Soup }\end{array}$ \\
\hline Rice/Noodles & $\begin{array}{l}\text { Brown } \\
\text { Rice }\end{array}$ & $\begin{array}{l}\text { Brown } \\
\text { Rice }\end{array}$ & Noodles & $\begin{array}{l}\text { Brown } \\
\text { Rice }\end{array}$ & $\begin{array}{l}\text { Brown } \\
\text { Rice }\end{array}$ & White Rice & $\begin{array}{l}\text { Brown } \\
\text { Rice }\end{array}$ & White Rice & Noodles & $\begin{array}{l}\text { White } \\
\text { Rice }\end{array}$ \\
\hline Type of Sauce & $\begin{array}{l}\text { Brown } \\
\text { Sauce }\end{array}$ & $\begin{array}{l}\text { Sweet and } \\
\text { Sour Sauce }\end{array}$ & $\begin{array}{l}\text { Brown } \\
\text { Sauce }\end{array}$ & $\begin{array}{l}\text { Sweet and } \\
\text { Sour Sauce }\end{array}$ & $\begin{array}{l}\text { Brown } \\
\text { Sauce }\end{array}$ & $\begin{array}{l}\text { Brown } \\
\text { Sauce }\end{array}$ & $\begin{array}{l}\text { Szechwan } \\
\text { Sauce }\end{array}$ & $\begin{array}{l}\text { Sweet and } \\
\text { Sour Sauce }\end{array}$ & $\begin{array}{l}\text { Sweet and } \\
\text { Sour Sauce }\end{array}$ & $\begin{array}{c}\text { Szechwan } \\
\text { Sauce }\end{array}$ \\
\hline $\begin{array}{c}\text { Type of } \\
\text { Vegetables }\end{array}$ & $\begin{array}{c}\text { Tofu \& } \\
\text { Exotic } \\
\text { Vegetables }\end{array}$ & $\begin{array}{c}\text { No } \\
\text { Vegetables }\end{array}$ & $\begin{array}{c}\text { Standard } \\
\text { Vegetables }\end{array}$ & $\begin{array}{c}\text { Tofu \& } \\
\text { Exotic } \\
\text { Vegetables }\end{array}$ & $\begin{array}{c}\text { Standard } \\
\text { Vegetables }\end{array}$ & $\begin{array}{c}\text { Tofu \& } \\
\text { Exotic } \\
\text { Vegetables }\end{array}$ & $\begin{array}{c}\text { Standard } \\
\text { Vegetables }\end{array}$ & $\begin{array}{c}\text { Standard } \\
\text { Vegetables }\end{array}$ & $\begin{array}{c}\text { Tofu \& } \\
\text { Exotic } \\
\text { Vegetables }\end{array}$ & $\begin{array}{c}\text { Standard } \\
\text { Vegetable } \\
\text { s }\end{array}$ \\
\hline Type of Meat & No Meat & Shrimp & Chicken & Shrimp & Shrimp & Beef & Beef & Shrimp & Shrimp & No Meat \\
\hline Spring Roll & $\begin{array}{c}\text { Pork } \\
\text { Spring Roll }\end{array}$ & $\begin{array}{l}\text { Vegetable } \\
\text { Spring Roll }\end{array}$ & $\begin{array}{l}\text { Vegetable } \\
\text { Spring Roll }\end{array}$ & $\begin{array}{l}\text { Vegetable } \\
\text { Spring Roll }\end{array}$ & $\begin{array}{c}\text { Pork } \\
\text { Spring Roll }\end{array}$ & $\begin{array}{l}\text { Vegetable } \\
\text { Spring Roll }\end{array}$ & $\begin{array}{l}\text { Vegetable } \\
\text { Spring Roll }\end{array}$ & $\begin{array}{l}\text { Vegetable } \\
\text { Spring Roll }\end{array}$ & $\begin{array}{c}\text { Pork } \\
\text { Spring Roll }\end{array}$ & $\begin{array}{c}\text { Vegetable } \\
\text { Spring } \\
\text { Roll }\end{array}$ \\
\hline Quantity & Pint & Quart & Quart & Pint & Pint & Quart & Quart & Quart & Pint & Quart \\
\hline Price & $\$ 4.99$ & $\$ 5.99$ & $\$ 4.99$ & $\$ 5.99$ & $\$ 4.99$ & $\$ 3.99$ & $\$ 4.99$ & $\$ 5.99$ & $\$ 3.99$ & $\$ 4.99$ \\
\hline
\end{tabular}




\begin{tabular}{|c|c|c|c|c|c|c|c|c|c|c|}
\hline Attributes & Meal 11 & Meal 12 & Meal 13 & Meal 14 & Meal 15 & Meal 16 & Meal 17 & Meal 18 & Meal 19 & Meal 20 \\
\hline Soup & $\begin{array}{l}\text { Hot \& Sour } \\
\text { Soup }\end{array}$ & $\begin{array}{l}\text { Hot \& Sour } \\
\text { Soup }\end{array}$ & None & $\begin{array}{l}\text { Egg Drop } \\
\text { Soup }\end{array}$ & $\begin{array}{l}\text { Hot \& Sour } \\
\text { Soup }\end{array}$ & None & $\begin{array}{l}\text { Egg Drop } \\
\text { Soup }\end{array}$ & $\begin{array}{l}\text { Hot \& Sour } \\
\text { Soup }\end{array}$ & $\begin{array}{l}\text { Hot \& Sour } \\
\text { Soup }\end{array}$ & None \\
\hline Rice/Noodles & White Rice & White Rice & Noodles & Noodles & $\begin{array}{l}\text { Brown } \\
\text { Rice }\end{array}$ & White Rice & Noodles & Noodles & Noodles & Noodles \\
\hline Type of Sauce & $\begin{array}{l}\text { Brown } \\
\text { Sauce }\end{array}$ & $\begin{array}{l}\text { Szechwan } \\
\text { Sauce }\end{array}$ & $\begin{array}{c}\text { Szechwan } \\
\text { Sauce }\end{array}$ & $\begin{array}{l}\text { Brown } \\
\text { Sauce }\end{array}$ & $\begin{array}{l}\text { Sweet and } \\
\text { Sour Sauce }\end{array}$ & $\begin{array}{l}\text { Brown } \\
\text { Sauce }\end{array}$ & $\begin{array}{l}\text { Sweet and } \\
\text { Sour Sauce }\end{array}$ & $\begin{array}{l}\text { Brown } \\
\text { Sauce }\end{array}$ & $\begin{array}{c}\text { Szechwan } \\
\text { Sauce }\end{array}$ & $\begin{array}{l}\text { Sweet and } \\
\text { Sour Sauce }\end{array}$ \\
\hline $\begin{array}{c}\text { Type of } \\
\text { Vegetables }\end{array}$ & $\begin{array}{c}\text { Tofu \& } \\
\text { Exotic } \\
\text { Vegetables }\end{array}$ & $\begin{array}{c}\text { Tofu \& } \\
\text { Exotic } \\
\text { Vegetables }\end{array}$ & $\begin{array}{c}\text { No } \\
\text { Vegetables }\end{array}$ & $\begin{array}{c}\text { Standard } \\
\text { Vegetables }\end{array}$ & $\begin{array}{c}\text { Tofu \& } \\
\text { Exotic } \\
\text { Vegetables }\end{array}$ & $\begin{array}{c}\text { Standard } \\
\text { Vegetables }\end{array}$ & $\begin{array}{c}\text { Standard } \\
\text { Vegetables }\end{array}$ & $\begin{array}{c}\text { No } \\
\text { Vegetables }\end{array}$ & $\begin{array}{c}\text { Tofu \& } \\
\text { Exotic } \\
\text { Vegetables }\end{array}$ & $\begin{array}{c}\text { Tofu \& } \\
\text { Exotic } \\
\text { Vegetables }\end{array}$ \\
\hline Type of Meat & Beef & Shrimp & Beef & Beef & Shrimp & No Meat & Chicken & Beef & Chicken & No Meat \\
\hline Spring Roll & $\begin{array}{l}\text { Vegetable } \\
\text { Spring Roll }\end{array}$ & $\begin{array}{c}\text { Pork } \\
\text { Spring Roll }\end{array}$ & $\begin{array}{c}\text { Pork } \\
\text { Spring Roll }\end{array}$ & $\begin{array}{c}\text { Pork } \\
\text { Spring Roll }\end{array}$ & $\begin{array}{l}\text { Vegetable } \\
\text { Spring Roll }\end{array}$ & $\begin{array}{l}\text { Vegetable } \\
\text { Spring Roll }\end{array}$ & $\begin{array}{c}\text { Vegetable } \\
\text { Spring Roll }\end{array}$ & $\begin{array}{c}\text { Pork } \\
\text { Spring Roll }\end{array}$ & $\begin{array}{c}\text { Pork } \\
\text { Spring Roll }\end{array}$ & $\begin{array}{c}\text { Vegetable } \\
\text { Spring Roll }\end{array}$ \\
\hline Quantity & Pint & Pint & Pint & Quart & Quart & Pint & Pint & Quart & Quart & Pint \\
\hline Price & $\$ 3.99$ & $\$ 4.99$ & $\$ 3.99$ & $\$ 5.99$ & $\$ 5.99$ & $\$ 3.99$ & $\$ 3.99$ & $\$ 4.99$ & $\$ 5.99$ & $\$ 4.99$ \\
\hline
\end{tabular}




\section{APPENDIX 3. EXPERIMENTAL INSTRUCTIONS FOR STUDY 2}

In this Appendix, we provide the exact instructions for the experiment conducted in Study 2. Each subject read the specific instructions for the experimental condition to which he or she was assigned. We also include one conjoint task example.

\section{$\underline{\text { Instruction for Hypothetical (Traditional) Conjoint }}$}

You are about to participate in an experiment designed to understand how people like you value a variety of snacks. We would ask that you pay close attention to the different snacks being offered and determine an accurate value for each meal. You will be shown 27 sets of three snack combos. For each set of three combos, imagine that you were asked to choose between no snack and one of these three different snacks at the stated price. Select the most attractive option (which could include not selecting any of the snacks).

\section{$\underline{\text { Instruction for Incentive-Aligned Conjoint }}$}

You are about to participate in an experiment designed to understand how people like you value a variety of snacks. We would ask that you pay close attention to the different snacks being offered and determine an accurate value for each combo. You now have an opportunity to purchase a snack combo. Here is how it works. You will be shown 27 sets of three combos. For each set of three combos, please choose between no snack and one of these three different combos at the stated price. After you complete your selection, we will randomly choose a set from these 27 sets, and your choice for that set will be fulfilled. If you have selected no snack for that set, you will be given $\$ 3$ cash; if you have selected a snack combo for that set, you will be given $\$ 3$ minus the price of that combo as stated, in addition to the actual snack combo.

Remember, the choice you make here in the experiment will be fulfilled (you will receive the actual snack combo selected by you).

\section{An Example of the Conjoint Task}

\begin{tabular}{|c|c|c|c|c|}
\hline 1 & $\$ 2.50$ Water & Peanut Butter & Korean Strawberry Cereal Bar & Banana \\
\hline 2 & $\$ 1.75$ Orange Juice & Peanut Butter & No Korean Cereal Bar & Apple \\
\hline 3 & $\$ 2.50$ Diet Coke & Chocolate Fudge & Korean White Chocolate Cereal Bar & Banana \\
\hline
\end{tabular}

Please indicate your most preferred choice:

\section{Combo 1}

Combo 2

Combo 3

Don't want to purchase any combo from this page 


\section{APPENDIX 4. HOLDOUT TASK FOR STUDY 2}

You will receive $\$ 3$, and you can use it to purchase the snack. Please select the combo that you will be interested to buy (just one) or, in the case you are not interested in any of them, indicate as such:

I want to buy combo \#

I do not want to buy any combo

30 Available Snack Combos

\begin{tabular}{|c|c|c|c|c|c|}
\hline $\begin{array}{c}\text { Item } \\
\#\end{array}$ & Price & $\begin{array}{c}\text { Drink } \\
\text { Included }\end{array}$ & $\begin{array}{l}\text { Cookie } \\
\text { Included }\end{array}$ & Korean Cereal Bar Included & Fruit Included \\
\hline 1 & $\$ 1.00$ & Coke & No Cookie & No Korean Cereal Bar & Banana \\
\hline 2 & $\$ 1.00$ & Ice Tea & Oatmeal Raisin & Korean White Chocolate Cereal Bar & Banana \\
\hline 3 & $\$ 1.75$ & Coke & Chocolate Fudge & No Korean Cereal Bar & Apple \\
\hline 4 & $\$ 2.50$ & Coke & Oatmeal Raisin & No Korean Cereal Bar & No Fruit \\
\hline 5 & $\$ 1.75$ & Ice Tea & Chocolate Fudge & Korean White Chocolate Cereal Bar & Banana \\
\hline 6 & $\$ 1.75$ & Coke & Chocolate Fudge & Korean Dark Chocolate Cereal Bar & Apple \\
\hline 7 & $\$ 1.00$ & Water & Chocolate Fudge & Korean Dark Chocolate Cereal Bar & Apple \\
\hline 8 & $\$ 1.00$ & Coke & Peanut Butter & Korean Dark Chocolate Cereal Bar & No Fruit \\
\hline 9 & $\$ 2.50$ & Orange Juice & Chocolate Fudge & Korean Dark Chocolate Cereal Bar & Apple \\
\hline 10 & $\$ 2.50$ & Water & No Cookie & Korean Strawberry Cereal Bar & Banana \\
\hline 11 & $\$ 2.50$ & Diet Coke & No Cookie & Korean White Chocolate Cereal Bar & Apple \\
\hline 12 & $\$ 1.00$ & Diet Coke & Peanut Butter & Korean White Chocolate Cereal Bar & No Fruit \\
\hline 13 & $\$ 2.50$ & Orange Juice & Peanut Butter & No Korean Cereal Bar & Apple \\
\hline 14 & $\$ 1.75$ & Water & Oatmeal Raisin & No Korean Cereal Bar & No Fruit \\
\hline 15 & $\$ 2.50$ & Orange Juice & Peanut Butter & Korean Dark Chocolate Cereal Bar & Apple \\
\hline 16 & $\$ 2.50$ & Diet Coke & No Cookie & Korean Dark Chocolate Cereal Bar & No Fruit \\
\hline 17 & $\$ 2.50$ & Orange Juice & Chocolate Fudge & No Korean Cereal Bar & Banana \\
\hline 18 & $\$ 1.00$ & Coke & Chocolate Fudge & Korean Strawberry Cereal Bar & No Fruit \\
\hline 19 & $\$ 2.50$ & Orange Juice & Oatmeal Raisin & Korean White Chocolate Cereal Bar & No Fruit \\
\hline 20 & $\$ 1.75$ & Ice Tea & No Cookie & Korean Dark Chocolate Cereal Bar & No Fruit \\
\hline 21 & $\$ 1.75$ & Water & Peanut Butter & Korean White Chocolate Cereal Bar & Banana \\
\hline 22 & $\$ 2.50$ & Diet Coke & Peanut Butter & Korean Dark Chocolate Cereal Bar & No Fruit \\
\hline 23 & $\$ 1.00$ & Ice Tea & Chocolate Fudge & Korean Strawberry Cereal Bar & No Fruit \\
\hline 24 & $\$ 2.50$ & Water & Chocolate Fudge & No Korean Cereal Bar & No Fruit \\
\hline 25 & $\$ 1.75$ & Ice Tea & Peanut Butter & Korean Dark Chocolate Cereal Bar & Banana \\
\hline 26 & $\$ 2.50$ & Ice Tea & Chocolate Fudge & Korean White Chocolate Cereal Bar & Banana \\
\hline 27 & $\$ 2.50$ & Coke & No Cookie & Korean Strawberry Cereal Bar & Banana \\
\hline 28 & $\$ 2.50$ & Coke & Oatmeal Raisin & Korean Strawberry Cereal Bar & No Fruit \\
\hline 29 & $\$ 1.75$ & Ice Tea & Chocolate Fudge & Korean Dark Chocolate Cereal Bar & Banana \\
\hline 30 & $\$ 1.75$ & Orange Juice & No Cookie & Korean Strawberry Cereal Bar & No Fruit \\
\hline
\end{tabular}




\section{Predictive Performance for Holdout Task: Study 1}

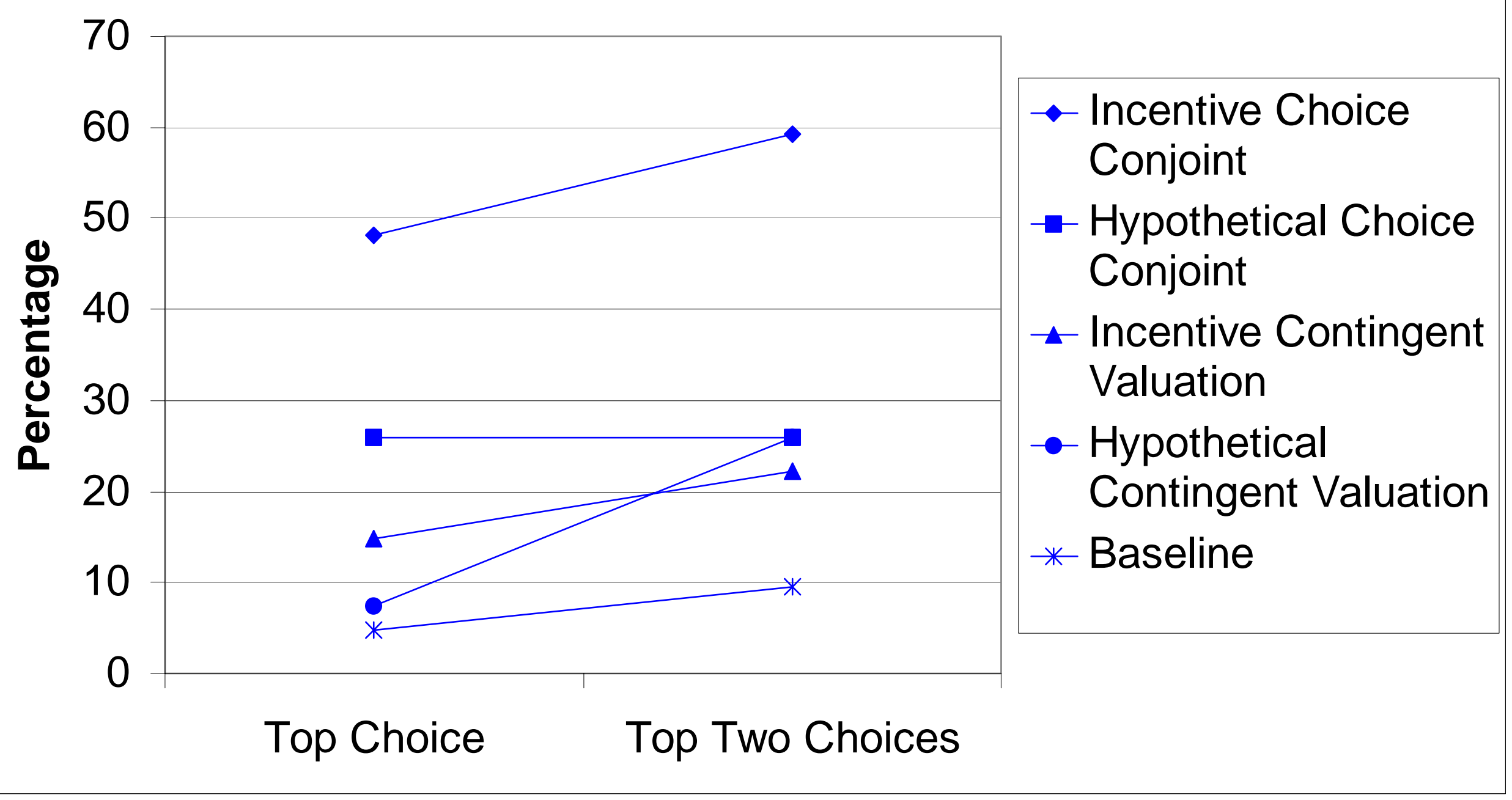




\section{Predictive Performance for Holdout Task: Study 2}

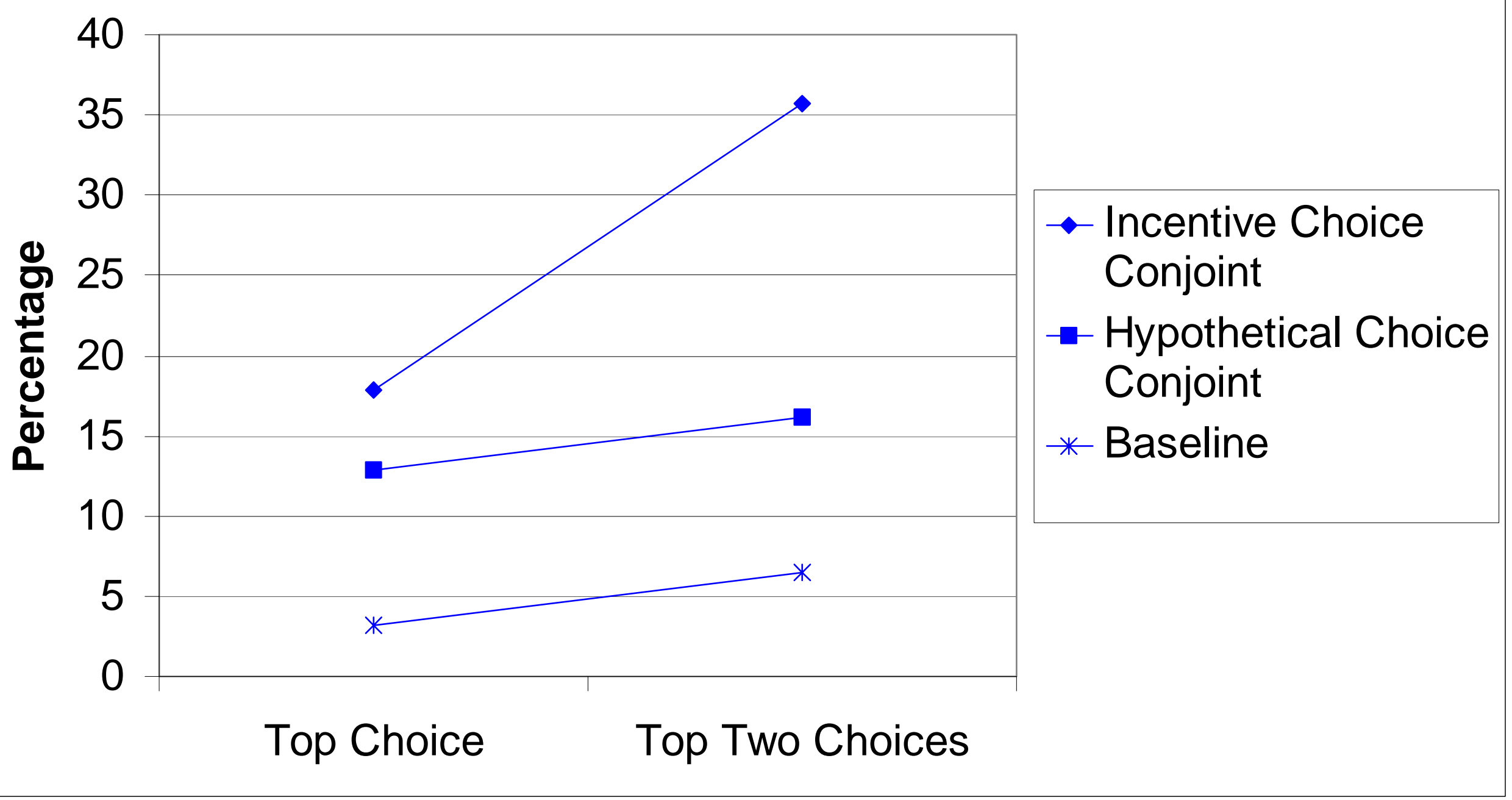


Table 1

Summaries of Parameter Estimates for Choice Conjoint Method (Random Effects Logit Analysis)

\begin{tabular}{|c|c|c|c|c|c|c|c|c|c|c|c|c|c|c|c|c|}
\hline & Parameter** & Intercept & $\begin{array}{l}\text { Hot \& } \\
\text { Sour } \\
\text { Soup }\end{array}$ & $\mid \begin{array}{c}\text { Egg Drop } \\
\text { Soup }\end{array}$ & $\begin{array}{l}\text { Brown } \\
\text { Rice }\end{array}$ & Noodles & $\begin{array}{l}\text { Szechwan } \\
\text { Sauce }\end{array}$ & $\begin{array}{c}\text { Sweet \& Sour } \\
\text { Sauce }\end{array}$ & $\begin{array}{c}\text { Standard } \\
\text { Vegetables }\end{array}$ & $\begin{array}{c}\text { Exotic } \\
\text { Vegetables }\end{array}$ & Beef & Chicken & Shrimp & $\begin{array}{c}\text { Pork Spring } \\
\text { Roll }\end{array}$ & Quart & Price \\
\hline \multirow{3}{*}{$\begin{array}{c}\text { Incentive } \\
\text { Conjoint }\end{array}$} & $\begin{array}{l}\text { Slope } \\
\text { (Mean*) }\end{array}$ & 2.62 & -.76 & .43 & .28 & .42 & -.17 & .01 & 1.46 & .23 & 2.66 & 3.42 & 2.48 & -.60 & .40 & -1.59 \\
\hline & Slope (Std $\left.{ }^{*}\right)$ & .65 & .59 & .47 & .48 & .54 & .59 & .52 & .44 & .52 & .49 & .64 & .61 & .47 & .39 & .19 \\
\hline & Slope (Het $\left.{ }^{*}\right)$ & .82 & 7.15 & 3.11 & .99 & 1.18 & 4.91 & 3.13 & 1.02 & 2.99 & 2.07 & 6.14 & 5.44 & 3.74 & 1.26 & .44 \\
\hline \multirow{3}{*}{$\begin{array}{c}\text { Hypothetical } \\
\text { Conjoint }\end{array}$} & $\begin{array}{c}\text { Slope } \\
(\text { Mean*) }\end{array}$ & .67 & .56 & .55 & .58 & -.09 & .38 & .14 & 1.85 & 1.00 & 3.65 & 4.11 & 3.28 & -.80 & 1.29 & -.99 \\
\hline & Slope (Std*) & .57 & .45 & .50 & .52 & .52 & .41 & .36 & .44 & .55 & .91 & .93 & .91 & .51 & .46 & .26 \\
\hline & Slope (Het $\left.{ }^{*}\right)$ & 1.55 & 1.58 & 3.46 & 3.05 & 3.44 & 1.78 & .89 & .49 & 3.84 & 1.76 & 2.68 & 4.53 & 2.90 & 2.93 & .20 \\
\hline
\end{tabular}

*Posterior mean and standard deviation of $\overline{\widetilde{\beta}}$; heterogeneity and posterior mean of diagonal of $\tilde{\Lambda}$. Note that a simple 't-statistic' calculation (posterior mean)/(posterior standard deviation) gives guidance with respect to whether the marginal posterior density for each parameter is far away from zero; or whether the estimates have influence.

**Soups are compared with no soup, Brown Rice and Noodles are compared with White Rice, Sauces are compared with Brown Sauce,

Vegetables are compared with no vegetables, Meats are compared with no meat, Pork Spring Roll is compared with Vegetable Spring Roll, and Quart size is compared with Pint size. 
Table 2

Summaries of Parameter Estimates for Contingent Valuation Method (Random Effects Regression Analysis)

\begin{tabular}{|c|c|c|c|c|c|c|c|c|c|c|c|c|c|c|c|c|}
\hline & Parameter ${ }^{\star *}$ & Intercept & $\begin{array}{c}\text { Hot \&Sour } \\
\text { Soup }\end{array}$ & $\begin{array}{c}\text { Egg Drop } \\
\text { Soup }\end{array}$ & $\begin{array}{l}\text { Brown } \\
\text { Rice }\end{array}$ & Noodles & $\begin{array}{l}\text { Szechwan } \\
\text { Sauce }\end{array}$ & $\begin{array}{c}\text { Sweet \&Sour } \\
\text { Sauce }\end{array}$ & $\begin{array}{c}\text { Standard } \\
\text { Vegetables }\end{array}$ & $\begin{array}{c}\text { Exotic } \\
\text { Vegetables }\end{array}$ & Beef & Chicken & Shrimp & $\begin{array}{c}\text { Pork } \\
\text { Spring } \\
\text { Roll }\end{array}$ & Quart & Sigma \\
\hline \multirow{3}{*}{$\begin{array}{l}\text { Incentive } \\
\text { Conjoint }\end{array}$} & $\begin{array}{l}\text { Slope } \\
\text { (Mean*) }\end{array}$ & 2.36 & .27 & .55 & .05 & .13 & -.05 & .16 & .48 & .37 & 1.14 & 1.06 & .89 & .19 & .64 & .66 \\
\hline & Slope (Std $\left.{ }^{*}\right)$ & .38 & .29 & .30 & .29 & .29 & .27 & .27 & .27 & .27 & .35 & .30 & .32 & .28 & .27 & .10 \\
\hline & Slope $\left(\mathrm{Het}^{*}\right)$ & 2.06 & 1.23 & 1.04 & 1.01 & 1.05 & 1.02 & 1.02 & 1.06 & 1.11 & 1.69 & 1.23 & 1.61 & 1.64 & 1.18 & -- \\
\hline \multirow{3}{*}{$\begin{array}{c}\text { Hypothetical } \\
\text { Conjoint }\end{array}$} & $\begin{array}{c}\text { Slope } \\
\left(\text { Mean* }^{\star}\right)\end{array}$ & 2.88 & .34 & .12 & .02 & -.02 & .07 & .09 & .45 & .21 & 1.23 & 1.28 & 1.67 & .05 & .86 & .55 \\
\hline & Slope (Std $\left.{ }^{*}\right)$ & .32 & .27 & .28 & .28 & .26 & .26 & .25 & .25 & .30 & .31 & .27 & .28 & .21 & .25 & .10 \\
\hline & Slope $\left(\mathrm{Het}^{*}\right)$ & 1.23 & 1.03 & 1.14 & .98 & .94 & .97 & .96 & .96 & 1.81 & 1.22 & .91 & 1.07 & .77 & 1.00 & -- \\
\hline
\end{tabular}

*Posterior mean and standard deviation of $\bar{\beta}$; heterogeneity and posterior mean of diagonal of $\Lambda$. Note that a simple 't-statistic' calculation (posterior mean)/(posterior standard deviation) gives guidance with respect to whether the marginal posterior density for each parameter is far away from zero; or whether the estimates have influence.

**Soups are compared with no soup, Brown Rice and Noodles are compared with White Rice, Sauces are compared with Brown Sauce, Vegetables are compared with no vegetables, Meats are compared with no meat, Pork Spring Roll is compared with Vegetable Spring Roll, and Quart size is compared with Pint size. 
Table 3

Summaries of Parameter Estimates for Choice Conjoint Method (Random Effects Logit Analysis)

\begin{tabular}{|c|c|c|c|c|c|c|c|c|c|c|c|c|c|c|c|}
\hline & Parameter** & $\begin{array}{l}\text { Intercept } \\
\text { (Coke) }\end{array}$ & $\begin{array}{l}\text { Diet } \\
\text { Coke }\end{array}$ & $\begin{array}{l}\text { Orange } \\
\text { Juice }\end{array}$ & Ice Tea & Water & $\begin{array}{l}\text { Oatmeal } \\
\text { Cookie }\end{array}$ & $\begin{array}{c}\text { Chocolate } \\
\text { Fudge Cookie }\end{array}$ & $\begin{array}{l}\text { Peanut- } \\
\text { butter } \\
\text { Cookie }\end{array}$ & \begin{tabular}{|c|} 
White \\
Chocolate \\
Korean Snack \\
bar
\end{tabular} & $\begin{array}{c}\text { Strawberry } \\
\text { Korean Snack } \\
\text { bar }\end{array}$ & $\begin{array}{c}\text { Dark } \\
\text { Chocolate } \\
\text { Korean Snack } \\
\text { bar } \\
\end{array}$ & Banana & Apple & Price \\
\hline \multirow{3}{*}{$\begin{array}{l}\text { Incentive } \\
\text { Conjoint }\end{array}$} & $\begin{array}{c}\text { Slope } \\
\text { (Mean*) }\end{array}$ & 2.11 & -1.84 & 0.16 & 1.10 & 1.43 & 1.87 & 2.27 & 2.15 & 0.35 & 0.38 & 0.47 & 0.88 & 0.62 & -4.18 \\
\hline & Slope (Std*) & 0.92 & 1.24 & 0.63 & 0.41 & 0.78 & 0.58 & 0.50 & 0.51 & 0.30 & 0.36 & 0.35 & 0.57 & 0.53 & 0.57 \\
\hline & Slope (Het $\left.{ }^{*}\right)$ & 12.96 & 40.37 & 8.56 & 2.26 & 11.14 & 6.49 & 3.73 & 3.59 & 0.50 & 1.08 & 2.03 & 5.71 & 4.69 & 5.60 \\
\hline \multirow{3}{*}{$\begin{array}{c}\text { Hypothetical } \\
\text { Conjoint }\end{array}$} & $\begin{array}{c}\text { Slope } \\
\left(\text { Mean* }^{\star}\right)\end{array}$ & 1.48 & -3.94 & -0.44 & -0.29 & -0.13 & 0.57 & 2.22 & 2.80 & 0.63 & 0.73 & 0.79 & 1.44 & 0.85 & $\mid-2.61$ \\
\hline & Slope $\left(\mathrm{Std}^{*}\right)$ & 0.59 & 0.90 & 0.49 & 0.59 & 0.63 & 0.51 & 0.49 & 0.54 & 0.41 & 0.34 & 0.36 & 0.30 & 0.26 & 0.25 \\
\hline & Slope (Het $\left.{ }^{*}\right)$ & 5.79 & 18.79 & 5.52 & 8.57 & 9.35 & 4.49 & 4.82 & 5.95 & 3.16 & 1.97 & 2.56 & 1.32 & 0.91 & 0.90 \\
\hline
\end{tabular}

*Posterior mean and standard deviation of $\overline{\widetilde{\beta}}$; heterogeneity and posterior mean of diagonal of $\tilde{\Lambda}$. Note that a simple 't-statistic' calculation (posterior mean)/(posterior standard deviation) gives guidance with respect to whether the marginal posterior density for each parameter is far away from zero; or whether the estimates have influence.

**Cookies are compared with no cookie, Korean snacks are compared with no Korean snacks, and fruits are compared with no fruit. 